\title{
A physical understanding of large intraplate earthquakes
}

\author{
${\text { Yoshihisa } \text { Iio }^{1 *} \text { and Yoji Kobayashi }}^{2}$ \\ ${ }^{1}$ Earthquake Research Institute, the University of Tokyo, Yayoi 1-1-1, Bunkyo-ku, Tokyo 113-0032, Japan \\ ${ }^{2}$ Institute for Geoscience, University of Tsukuba, Tsukuba, Ibaragi 305-0006, Japan
}

(Received December 27, 2001; Revised August 10, 2002; Accepted August 12, 2002)

\begin{abstract}
We examined several previously proposed models of the process by which large intraplate earthquakes are generated, and found the most plausible to be the 'localized shear model,' in which seismogenic faults have downward extensions in the lower crust and the localized shear deformation on the downward extensions accumulate stress on the seismogenic faults. Further, localized shear deformation may accelerate before a large intraplate earthquake occurs. This model can explain various phenomena related to crustal deformation in the Japanese Islands: preslips, seismicity, distribution of active faults, and stress and strain state. It will play an important role in the forecasting and prediction of large intraplate earthquakes.
\end{abstract}

\section{Introduction}

Intraplate earthquakes occur in the upper crust, which is regarded as a purely elastic medium. There are two end-member models of the process by which intraplate earthquakes are generated. In the 'regional stress model' (Fig. 1(a)), broad-scale uniform regional stress generates intraplate earthquakes on low-strength pre-existing faults in the upper crust (e.g., Sykes, 1978; Hinze et al., 1988; Johnston and Kanter, 1990; Zoback, 1992). Alternatively, in the 'local stress model' (Figs. 1(b)-(e)), concentrations of local stress generate intraplate earthquakes (e.g., Campbell, 1978; Liu and Zoback, 1997; Stuart et al., 1997). Several mechanisms have been proposed to explain such concentrations and the local stress model is classified into two sub-groups, the 'lowstrength model' (Figs. 1(b), (c)) and the 'basal drag model' (Figs. 1(d), (e)).

In the 'low-strength model', stress accumulates in the upper crust above the regions of low viscosity in the lower crust and/or upper mantle (Liu and Zoback, 1997; Kenner and Segall, 2000). This stress probably accumulates as a result of high temperature or high water content (e.g., Goetze and Evans, 1979; Griggs and Blacic, 1965). There are two possibilities for the spatial distribution of low viscosity: it is either confined to a localized ductile fault zone (e.g., Iio, 1996; Stuart et al., 1997), or is widely distributed in a volume (e.g., Liu and Zoback, 1997; Kenner and Segall, 2000).

The local stress concentration might be caused instead by basal drag at the bottom of the crust or lithosphere, resulting from mantle convection or plume (the 'basal drag model,' Figs. 1(d), (e)). However, it is still controversial as to whether a plume or upwelling, as opposed to a broad-scale

* Present address: Disaster Prevention Research Institute, Kyoto University, Gokasho, Uji, Kyoto 611-0011, Japan.

Copy right (C) The Society of Geomagnetism and Earth, Planetary and Space Sciences (SGEPSS); The Seismological Society of Japan; The Volcanological Society of Japan; The Geodetic Society of Japan; The Japanese Society for Planetary Sciences. extensional force, causes continental rifting (e.g., Story, 1995). If a plume or upwelling were responsible for rifting in extensional zones, there would then be two possibilities for the style of deformation in the lower crust below the seismogenic faults and the mechanism by which stress accumulates in the upper crust. One possibility is called distributed pure shear (e.g., Mckenzie, 1978), and the other is called localized simple shear (e.g., Wernicke, 1981). In a convergent zone, also, a simulation by Hager et al. (1999) indicated that strains accumulate by inhomogeneity of the ductile flow in the lower crust under basal drag and far-field convergent boundary conditions.

The main purpose of this paper is to determine the most plausible model based on the existing data. First we examine the regional stress model, based on intraplate seismicity and a distribution of active faults in Japan. We then examine the local stress model. Based on the style of deformation in the lower crust, the local stress model can be classified into two sub-groups, the 'distributed and localized shear models,' that are different from the two sub-groups classified based on the mechanism of stress concentration. Although the driving force of deformation in the lower crust differs between the 'low-strength model' and the 'basal drag model', the mechanism of stress accumulation in the upper crust is very similar, since in both models stress accumulates in the upper crust by deformation in the lower crust. We therefore focus on the question of whether the deformation in the lower crust is localized or distributed.

It is a common idea among 'geologists' who investigate exposed ductile fault zones that deformation in the lower crust is localized in a narrow fault zone (e.g., Sibson, 1983). The causes of localization are suggested to be water (e.g., Kronenberg et al., 1990; McCaig, 1997) and/or small grain sizes (e.g., Bell and Etheridge, 1973). However, as shown in the above, this is not necessarily a common idea for intraplate earthquakes among 'geophysicists'. Therefore, it is essential in this paper to clarify whether or not the ductile 


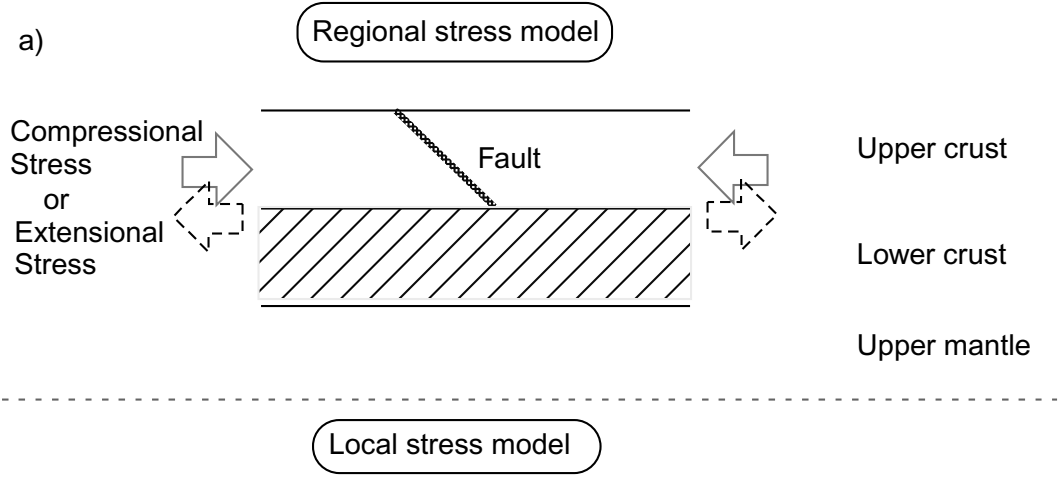

b)

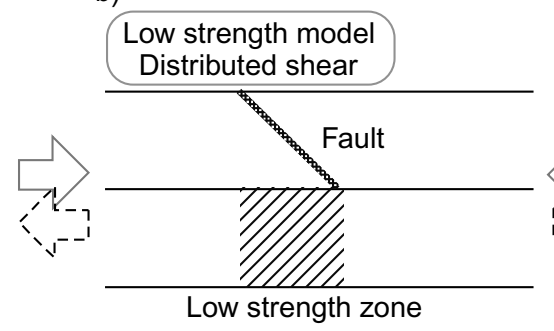

d)

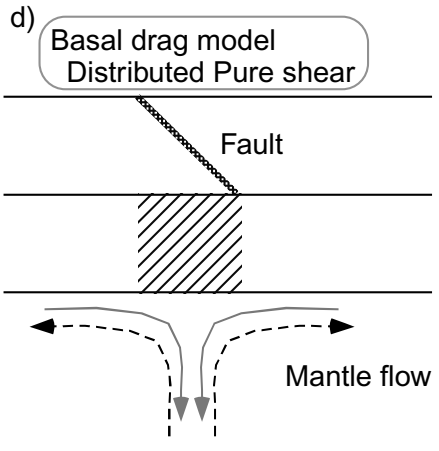

Distributed shear model c)

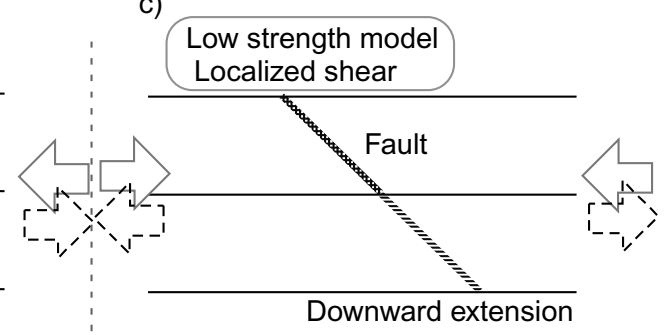

e) Basal drag model Localized simple shear

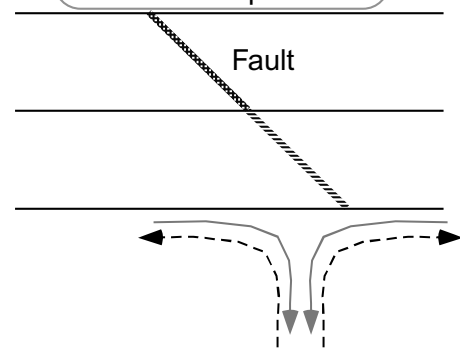

Localized shear mode

Fig. 1. Schematic drawings showing the regional stress model (a) and the local stress model (b)-(e) for the generating process of intraplate earthquakes. The local stress model is classified into two sub-groups, the low-strength model (b), (c) and the basal drag model (d), (e). On the other hand, the local stress model can be classified into two groups according not to the manner of stress concentration but to the style of deformation in the lower crust: the distributed shear model and the localized shear model.

flow is localized in a narrow zone in the lower crust - that is, whether or not seismogenic faults have downward extensions in the lower crust - by analyzing geophysical data.

In this paper, the terms 'upper crust' and 'lower crust' mean, respectively, the crust from the earth surface to the bottom of the seismogenic region and the crust below the seismogenic region.

2. Characteristics of Large Intraplate Earthquakes That Do Not Favor the Regional Stress Model-Why Don't Intraplate Earthquakes in Japan Trigger Successive Large Earthquakes in the Regions Next to Their Faults?-

From the catalogue of large earthquakes occurring in Japan in the past 400 years, it can be inferred that large intraplate earthquakes do not trigger successive large earthquakes in the regions next to their faults (see figure 5 in Wesnousky et al., 1982). Although this inference was based on only 400 years of catalogued data, i.e., covering less than a full intraplate earthquake cycle, it is consistent with the characteristics of active faults in Japan that have resulted from successive large intraplate earthquakes (Research Group for Active Faults in Japan, 1980; Wesnousky et al., 1982). The active faults or active fault systems in Japan necessarily have their ends and do not extend to distances the length of plate boundary faults, except in a few exceptions, such as Median Tectonic Lines (Research Group for Active Faults in Japan, 1980).

This suggests that, when the upper crust is assumed to be purely elastic, uniform regional stress is not the only cause of large intraplate earthquakes. If uniform regional stress were the only cause, the occurrence of a large intraplate earthquake would add large stress concentrations to the uniform regional stress level around both ends of the faults, as shown in Fig. 2. It is likely that the regions of these large stress concentrations in the 'regional stress model' are much wider 
a)

Regional stress model

Shear stress

on the fault
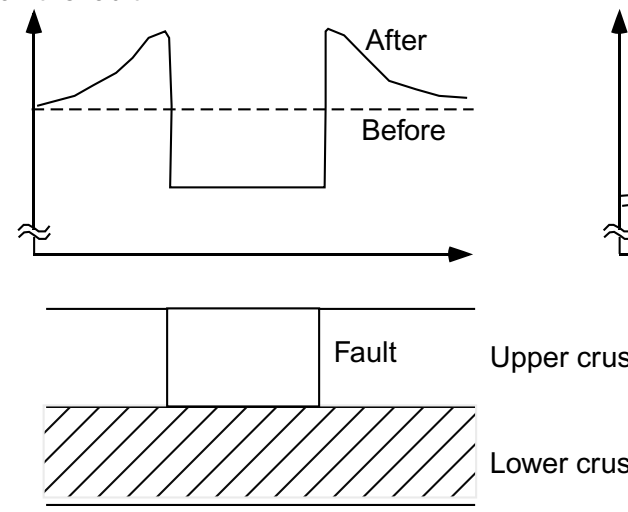

Upper mantle b) Local stress model
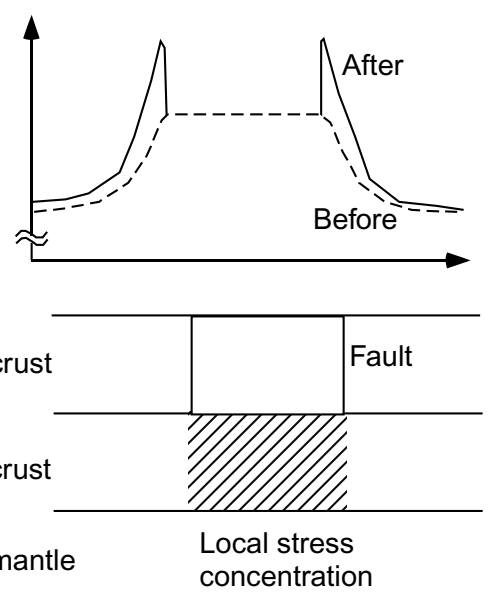

Fig. 2. Schematic drawings showing that a large intraplate earthquake adds large stress concentrations to the uniform regional stress level around both ends of faults. Dashed and solid lines show shear stress before and after a large intraplate earthquake occurs, respectively.

than those in 'local stress model.' Further, stress would accumulate by repeated large intraplate earthquakes and the regions next to the fault would be subjected to much greater stress, as long as the upper crust was still elastic. However, as pointed out above, it is very seldom that successive large earthquakes occur in the regions next to faults in intraplate Japan. This suggests that regional stress is not significant and that local stress concentrations are generated on the faults of the large intraplate earthquakes.

\section{Characteristics that Support the 'Localized Shear Model'}

\subsection{Cut-off depth of seismicity in and around the No-} jima fault

The cut-off depth of seismicity in and around the Nojima fault, broken by the 1995 Kobe earthquake occurring in intraplate Japan, was compared with the brittle-plastic transition depth of the widely accepted strength profile model of the crust (Iio and Kobayashi, 2002). In and around the Nojima fault, excellent temperature profiles were obtained from boreholes to a depth of about 1 or $2 \mathrm{~km}$ (Kitajima et al., 2001; Yamano and Goto, 2001). Thermal conductivities and heat production were also precisely measured from core samples. Using these data, the temperature in a deeper crust was successfully estimated. It was found that the observed cut-off depth is much deeper than the transition depth, under the assumption that wet granite is deformed at a strain rate of $3 \times 10^{-15} / \mathrm{s}$. This strain rate implies that the plastic flow is distributed uniformly below the seismogenic region. In other words, there is no downward extension of the seismogenic fault. On the other hand, when the strain rate is set as greater than $10^{-13} / \mathrm{s}$, the observed cut-off depth can be attributed to the transition depth. This suggests that deformation is localized in a narrow fault zone below the seismogenic region even in the intraplate region. In other words, in this case there is a downward extension of the seismogenic fault in the lower crust.

\subsection{Estimated aseismic slips on the downward exten- sions}

Here, we introduce anomalous crustal deformations before two large earthquakes occurring in and around the Japanese Islands in recent years. These deformations suggest that aseismic slips (localized shear deformation) actually occurred on the downward extensions of the seismogenic faults (Tada, 1984, 1987; Iio et al., 2002). We consider these data to be reliable because they were either observed at multiple sites and for multiple periods, or else were similar to the postseismic deformations.

Anomalous uplifts were observed before the 1983 Japan Sea earthquake by leveling (Tada, 1984). They were detected at two peninsulas, Oga and Fukaura, at almost the same time. Further, at Oga peninsula, uplifts of about $2 \mathrm{~cm}$ were detected in two periods of different durations, 1969-1977 (approximately 8 years) and 1977-1981 (approximately 4 years). Consequently, these observations are considered reliable. It was inferred from these uplift data that preseismic slips occurred on the downward extensions (Tada, 1984), because coseismic changes were in subsidence at both peninsulas. The uplift at Oga peninsula was approximately $4 \mathrm{~cm}$ from 1969 to 1981, and it is explained by a slip of $0.4 \mathrm{~m}$ on the downward extensions. The average slip velocities in the two periods, as computed from the uplift data at Oga peninsula, were about $2.5 \mathrm{~cm} / \mathrm{y}$ from 1969 to 1977, and about $5 \mathrm{~cm} / \mathrm{y}$ from 1977 to 1981 . These results suggest that aseismic slips accelerated before the Japan Sea earthquake.

Anomalous uplifts before and after the 1982 Urakawaoki earthquake were also detected by leveling surveys (Tada, 1987). A preseismic slip of $0.7 \mathrm{~m}$ on the downward extension was inferred from the uplift data. The curve of the uplift in the preseismic period is similar to that in the post-seismic period. Thus, the preseismic slip is considered to be reliable because there are several examples of afterslips on the downward extensions of seismogenic faults (i.e., Shen et al., 1994; Savage and Svarc, 1997). The average slip velocity 
for the preseismic period is computed as approximately 5 $\mathrm{cm} /$ year. We cannot consider this slip velocity as a steadystate value, because it is comparable to those on plate boundary faults (Heki et al., 1999). This implies that the slip on the downward extension accelerated before the Urakawa-oki earthquake.

From these observations, we inferred that the aseismic slips occurred on the downward extensions, which were simply assumed to have the same plunges as the seismogenic faults. Although these inferences are not unique, they are the simplest and can explain the observations. The most important point concerning these observations is the possibility that aseismic slips accelerated before large earthquakes.

\section{Concluding Remarks}

In this paper, we examined several models of the process by which large intraplate earthquakes are generated, and found that the 'localized shear model' is the most plausible, in which seismogenic faults of intraplate earthquakes have downward extensions in the lower crust and aseismic slips on the downward extensions accumulate stress on the seismogenic faults. It was inferred from the anomalous crustal deformations before two large earthquakes occurring in and around the Japanese Islands in recent years that the aseismic slips occurred on the downward extensions of the seismogenic faults and accelerated before the large intraplate earthquakes. The acceleration of aseismic slips is a new scope in this study and is not included in the previously proposed models.

In this paper, we did not consider faulting modes (e.g., reverse, strike-slip, and normal faulting). This is because we simply assumed the downward extensions to have the same dip angles as the seismogenic faults. If the dip angles of the downward extensions are smaller than those in the seismogenic faults, slips on the downward extensions change not only the shear stress but also the normal stress on the seismogenic faults, and the magnitudes of the changes in the normal stress depend on the faulting modes. The problems concerning changes in dip angles with depth and the different faulting modes are beyond the scope of this paper and need further extensive studies.

The localized shear model including the acceleration of aseismic slips can explain various phenomena related to crustal deformation, i.e., preslips, distribution of active faults, and stress and strain state in the Japanese Islands. It will play an important role in the forecasting and prediction of large intraplate earthquakes. This model should be examined by extensive researches on intraplate earthquakes and the fields where they occur.

Acknowledgments. This study is partly supported by a grant from the Comprehensive Joint Research of the Special Coordination Funds for Promoting Science and Technology. The authors are grateful to Richard $\mathrm{H}$. Sibson and an anonymous reviewer for their thoughtful comments and suggestions.

\section{References}

Bell, T. H. and M. A. Etheridge, Microstructure of mylonite and their descriptive terminology, Lithos, 6, 337-348, 1973.

Campbell, D. L., Investigation of the stress-concentration mechanism for intraplate earthquakes, Geophys. Res. Lett., 5, 477-479, 1978.
Goetze, C. and B. Evans, Stress and temperature in the bending lithosphere as constrained by experimental rock mechanics, Geophys. J. R. Astron. Soc., 59, 463-478, 1979

Griggs, D. T. and J. D. Blacic, Quartz-anomalous weakness of synthetic crystal, Science, 147, 292-295, 1965

Hager, B. H., G. A. Lyzenga, A. Donnellan, and D. Dong, Reconciling rapid strain accumulation with deep seismogenic fault planes in the Ventura basin, California, J. Geophys. Res., 104, 25,207-25,219, 1999.

Heki, K., et al., The Amurian plate motion and current plate kinematics in eastern Asia, J. Geophys. Res., 104, 29,147-29,155, 1999.

Hinze, W. J., L. W. Braile, G. R. Keller, and E. G. Lidiak, Models for midcontinent tectonism: An update, Rev. Geophys., 26, 699-717, 1988.

Iio, Y., A possible generating process of the 1995 Southern Hyogo prefecture earthquake - stick of fault and slip on detachment-, Zisin 2, 49, 103-112, 1996.

Iio, Y. and Y. Kobayashi, Is the plastic flow uniformly distributed below the seismogenic region?, Earth Planets Space, 54, this issue, 1085-1090, 2002.

Iio, Y., Y. Kobayashi, and T. Tada, Large earthquakes initiate by the acceleration of slips on the downward extensions of seismogenic faults, Earth Planet. Sci. Lett., 2002 (in press).

Johnston, A. C. and L. R. Kanter, Earthquakes in stable continental crust, Sci. Am., 262(3), 68-75, 1990 .

Kenner, S. and P. Segall, A mechanical model for intraplate earthquakes: Application to the New Madrid, Science, 289, 2329-2332, 2000.

Kitajima, T., Y. Kobayashi, R. Ikeda, Y. Iio, and K. Omura, Terrestrial heat flow in Hirabayashi, Awaji, Island, Island Arc, 10, 318-325, 2001.

Kronenberg, A. K., P. Segall, and G. H. Wolf, Hydrolytic weakening and penetrative deformation within a natural shear zone, edited by A. G. Duba, W. B. Durham, J. W. Handin, and H. F. Wang, The brittle-ductile transition in rocks (The heard volume), Am. Geophys. Union, Geophys Monogr., 56, pp. 21-36, 1990.

Liu, L. and M. D. Zoback, Lithospheric strength and intraplate seismicity in the New Madrid seismic zone, Tectonics, 16, 585-595, 1997.

McCraig, A. M., Geochemistry of volatile fluid flow in shear zone, Deformation-enhanced fluid transport in the earth's crust and mantle, edited by M. B. Holness, pp. 227-266, Chapman \& Hall, London, 1997.

Mckenzie, D. P., Some remarks on the development of sedimentary basins, Earth Planet. Sci. Lett., 40, 25-32, 1978.

Research Group for Active Faults of Japan, Active faults in Japan, shee maps and inventories, Univ. of Tokyo, Tokyo, 1980.

Savage, J. C. and J. L. Svarc, Postseismic deformation associated with the 1992 Landers earthquake, southern California, J. Geophys. Res., 102 7,565-6,577, 1997.

Shen, Z. K., et al., Post-seismic deformation following the Landers earthquake, California, 28 June 1992, Bull. Seismol. Soc. Am., 84, 780-791, 1994.

Sibson, R., Continental fault structure and the shallow earthquake source, $J$. Geol. Soc. London, 140, 741-767, 1983.

Story, B. C., The role of mantle plumes in continental breakup: case histories from Gondowanaland, Nature, 377, 301-308, 1995.

Stuart, W. D., T. G. Hildenbrand, and R. W. Simpson, Stressing of the New Madrid seismic zone by a lower crust detachment fault, J. Geophys. Res., 102, 27,623-27,633, 1997.

Sykes, L. R., Intraplate seismicity, reactivation of preexisting zones of weakness, alkaline magmatism, and other tectonism postdating continental fragmentation, Rev. Geophys., 16, 621-688, 1978.

Tada, T., The 1983 Japan Sea earthquake and related crustal deformation, Earth Monthly, 6, 18-21, 1984.

Tada, T., Fault model of the 1982 Urakawa-oki earthquake and its tectonic significance, Zisin, 40, 27-37, 1987.

Wernicke, B., Low-angle normal faults in the Basin and Range province: nappe tectonics in an extending orogen, Nature, 291, 645-648, 1981.

Wesnousky, S. G., C. H. Scholz, and K. Shimazaki, Deformation of an island arc: Rate of moment release and crustal shortening in intraplate Japan determined from seismicity and quaternary fault data, J. Geophys. Res. 87, 6829-6852, 1982.

Yamano, M. and S. Goto, Long-term temperature monitoring in a borehole drilled into the Nojima fault, southwest Japan, Island Arc, 10, 326-335, 2001.

Zoback, M. L., Stress field constraints on intraplate seismicity in eastern North America, J. Geophs. Res., 97, 11,761-11,782, 1992

Y. Iio (e-mail: iio@rcep.dpri.kyoto-u.ac.jp) and Y. Kobayashi 